\title{
Companies' vision, mission, and core values focus on human resource management
}

\author{
Sraboni Akter \\ Human Resource Management discipline, Khulna University \\ sraboniakterhrm@gmail.com
}

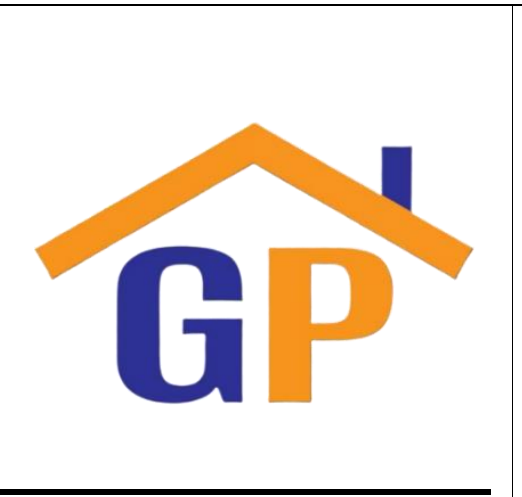

\section{Article History}

Received on 6 February 2021

$1^{\text {st }}$ Revision on 15 February 2021

$2^{\text {nd }}$ Revision on 24 February 2021

$3^{\text {rd }}$ Revision on 26 February 2021

Accepted on 1 March 2021

\begin{abstract}
Purpose: This study aimed to determine companies' vision, mission, and core values focus on human resource management.
\end{abstract}

Research methodology: This study used qualitative method and 14 companies' website has been used to identify their mission, vision and core values.

Results: From the total of 14 FMCG companies that had been used in this study only five (Akij group, Marco Bangladesh Reckitt Benckiser Group plc (RB), Eskayef Pharmaceuticals Ltd, and Danish) of them showed that they have no mention about the human resource management and nine of them showed their concern towards human capital in their vision, mission, and core values.

Limitation: This study is only confined to identify the mission, vision, core values, not their impact. Besides that, it is only limited to the small number of FMCG companies in Bangladesh.

Contribution: This study's results contribute to understanding the importance of focusing on human resource management on the companies' vision and mission and explaining the reason for modifying the existing statements.

Keywords: Core values, FMCG, Human resource management, Mission, Vision

How to cite: Akter, S. (2021). Companies' vision, mission, and core values focus on human resource management. International Journal of Financial, Accounting, and Management, 2(4), 343-355.

\section{Introduction}

Mission, vision, and core values are generally made when the firm is primarily set up and incorporates them into its strategic plan. In leadership theory, a mission statement is used synonymously and interchangeably with the vision statement, although the two statements are different from one another (DuFour et al. 2009). All of the recognized organizations make vision and mission, which acts as the basis for the organization's goal and those are critical and standard elements of a company's organizational strategy. Without a clear mission and vision, no organization will get any reputation towards the shareholders, stakeholders, and the customers but also harmful for the survival of that particular organization. The vision and mission of the company deliver a common logic of purpose, uniqueness, long-term intention and connect internally and externally with organization stakeholders (Kooli, C, 2019). But Creating the mission, vision, and values is also a continuous process of review to confirm that they are still appropriate for the present challenges, goals, and environment. Most of the companies find it beneficial to evaluate these at the beginning of their strategic plan development. The organization's Administration department must guarantee that the association runs reliably with its mission, vision, values, and ethical principles. These should be associated with the foundation for planning and monitoring, expenditures, activities, and decision-making and policies.

The historical work is overwhelmed with many academics who have faith that before making any mission or vision statements, management in any company must know what is in that particular business for the future to offer. In this way, the vision works as a foundation for the mission of the establishment. The vision gives a calculated framework, which works as the foundation for the mission and goals. 
Mission statements are primarily thought to be the primary source to any strategy design process (Darbi, W. P. K., 2012) and represent the cause for the presence and value for society at large. Mission statements are the theoretical way to carry on the path of success as a purpose of an organization in line with the values and perception of stakeholders and provide the answer to the following questions like "what business are we in?" and "What is our business for?" (Johnson et al., 2009). Mission statements have been reported as a broad framework around which other strategic aspects like vision, strategic intent, and capabilities, behavioral standards, goals, core values, objectives, business models, etc. evolve (Campbell and Tawadey, 1992). On the other hand, the Vision statement should include a perspective of corporate values and offer more than a direction.

The Fast-Moving Consumer Goods (FMCG) sector is one of the largest sectors in the economy of Bangladesh, which is known as well-established distribution networks, with a high level of competition and low operational costs. Being a developing economy, Bangladesh is slowly becoming a large marketplace, especially for the FMCG. In the last few years, the FMCG industry in Bangladesh has experienced a dramatic development. While buying high engrossment products like electronic goods, luxury items, or lifestyle-products, the prior in-home decisions of purchase are not usually altered in the store environment. On the contrary, for the convenient and low involvement products like salt, flours, pens, chocolates, etc., a significant level of distortion from the prior decision of brand choice is frequently observed. These convenient and low-involvement products are also-known as FMCG in marketing. According to the database of Registrar of Joint Stock of Companies and Firms (RJSC), there are 59 fast-moving consumer goods (FMCG) producer companies listed in the Registrar of Joint Stock of Companies, Bangladesh (FMCG, P. O. 2016). As any company's mission, vision shows the organization's real purpose, FMCG is not beyond that. It is a matter of regret that most of them are not showing any human capital statements. Their focus is only confined to companies' growth, not a mutual benefit of stakeholders. Some companies have shown their attention towards human resources but the criteria should be modified and shift to the broader aspect. Besides that, there has been no research that showed the focus on human resource management in companies' vision, mission, and core values in the past. It is one of the few studies that search for emphasis on change in mission and vision statements. It is essential to research since it is claimed that these statements can be used as a tool for organizational transformation. In particularly mission and vision statement literature, small sample researches have been conducted until today. To keep this significant research gap in mind this study intends only to find out Companies' vision, mission, and core values focus on human resource management through a comparative analysis and also to provide some suggestions regarding this matter.

Although this research provides useful empirical data to understand the concepts that companies are communicating with their formalized organizational statements, there is significant room for additional study. Future qualitative analysis projects should focus on understanding the actual proliferation of formalized organizational statements within organizations. This study does not attempt to answer the question of how many companies have formally written statements. Neither does it contemplate the number of different statements a company writes over time. Rather, our focus was on examining the conceptual framework inherent in mission statements. Since the data are over 10 years old and concentration have not been put since then. In addition, future research could investigate relationships between various concepts within the context of a statement. This would allow for gathering additional insights into what things are being communicated within each uniquely titled statement.

In addition, a universal framework could assist organizations in the development of these statements and create a sense of familiarity. there seems to be a need for additional research into the concept of density within statements. For instance, is there a correlation between a statement's density and the level of ownership within the organization? Is there a correlation between density and HRM focus? As for practical implications, executives will acknowledge that there is a widespread skepticism within many organizations today regarding the corporate mission statement. The understanding that vision and mission statements are exclusively meant for management or leadership is very usual among employees; nevertheless, they understand their significance to the organization. This study's limitations have important implications for future research given the challenge of identifying employee focus culture in the organization. Thus, future studies may need to incorporate methodologies and sample 
sizes beyond the scope of this study. Therefore, an increased sample size would strengthen the validity of the results. Future research may involve surveying the perceptions of more business owners or employees to increase both the internal and external validity of the results in this study. Also this study is only confined to identify the mission, vision, core values, not their impact. Besides that, it is only limited to FMCG companies of Bangladesh. There has been a broad scope in the future in this very topic, which can be done in other sectors like banking, educational institutions, and others. Furthermore, Various moderator factors can be used to get the real reason for not putting the human-centric focus on their mission and vision.

\section{Literature review}

\subsection{Mission}

Mission defines a clear, concise, and specific explanation of an organization's purpose, institution's establishment, curricular performance, culture and tradition, and current services and the existence of the organization and delineates in a specific language as well as it must be precise but at the same time, it should be stated in such a way to accommodate future plans, strategies, assumptions, and expectations of the organization (Hinton, K. E., 2012). The mission and vision statements signify the present and planned state of the establishment. The strategic plan used to grow the organization connections the gap between the two. DuFour and Eaker (2009) described a mission statement as stating the reason for a business and also responding to the inquiry, "Why do the organization exist. Lunenberg (2010) said that a continuing debate about the determination of the organization's survival is indispensable to the role of leadership. Most of the giant group like square also provides their mission statement which not only draw a picture about being best in the organization but also to ensure the rights of stakeholders as well as the society and their mission "is to produce and provide quality \& innovative healthcare relief for people, maintain stringently ethical standard in business operation also ensuring benefit to the shareholders, stakeholders and the society at large".

Stemler et al. (2011) conducted an inclusive content analysis of organizational mission statements and noted that, despite the existence of a clear school mission statement, stakeholders assign for a school's existence may differ widely and also among stakeholders within the same organization.

Stemler et al. (2011) argued that, while each of the perceived missions or purposes are indeed significant and admirable, the fact that such a wide variety of individually held or perceived purposes for organization and communal determination toward a standard set of objectives. This lack of harmony in defining a joint mission may result in a breakdown of mutual understanding. The purpose of emerging a widely shared organizational mission is not to limit others, rather focus on members' efforts in order to reach clearly articulated and specific goals (DuFour et al. 2009).

According to Boerema (2006), the mission statement of a company actually enunciates a set of principles that answer fundamental questions about the purpose also provides the framework for governance, decision making, and the way the institute is managed and he further enlightened that a mission statement offers a key route to those individuals performing the core expertise. The mission is an expected obligation of the company born from its social goals replicates the method in which vision can be transmuted into a perceptible existence for the company. Simply, a company lives because it must generate value for customers and satisfy their needs. The mission of an organization epitomizes the motive for existence and for creating value for society as well as synthesizes its vision (Bratianu, 2008).

\subsection{Vision}

Vision offers what the association wants to turn out to be and provides the route for the establishment's forthcoming. A vision statement is the countenance of the institution's goal, which is based on an analysis of the institution's situation (Hinton, K. E,2012). The vision statement encompasses the institution's comprehensive representation and eventual goal by keeping the organization's final aim in mind also a clear description of what it anticipates to become within a specific timeframe. The vision statement outlines the institution's prearranged spot in the future and the specific rudiments of that position with affiliation to the mission statement. It provides a piece of knowledge about the future 
growths of the organization. In short, it is the general goals of the organization. The model vision statement is the institution's endpoint for the strategic plan's dimension, which comprehends the exact features that will define the organization's future state and are used to inspire and stimulate future achievement. A vision statement is qualitatively different from a mission statement because it articulates not purpose but a favored imminent for the organization. DuFour and Eaker (2009), a vision statement response to what an organization hopes to become. Vision offers stakeholders an image of their ideal organization that successfully works together to achieve that vision. Nevertheless, a vision statement should be clear and meaningful to all stakeholders as an effective vision statement are brief and provide condescending, yet measurable (Pekarsky 2007) and also specified that a vision statement is far more than a motto. Stakeholders in a vision-guided organization, the functions are clearly articulated and supported, and they have a clear idea about where they are headed, what they are about, and how they will know when they have arrived.

Kose (2011) definite that a common, expressed vision is the distinctive source of powerful change in the organization on many different levels. (Bratianu, 2008) Stated that Vision is a strong integrator where People are sharing the same future picture of their organization will endeavor to find the best explanations to convert that vision into reality. Consequently, vision fits in the individual aids in knowledge, aptitude, and values from all employees. Vision also works as a driving force for growing latent organizational intellectual capital. Vision is an uncompromising forecast of the company in an approximate future, normally in a mature and successful position of what the company might be and might achieve. Still, the origins of this predictable image should be well distinct in the company's present business dynamics.

Between 1988 and 1994, Collins and Porras from Stanford University requested 700 CEO of U. S. companies of different size and ownership to recommend the firms they most respected and identified 18 visionary companies, most of them being long-lived and successful and the result showed that Visionary companies exhibit a powerful determination for development that allows them to change and adapt without compromising their valued core ideals (Porras and Collins, 2005). Calder, (2011) indicated six qualities of an organization's vision as Powerful, Purposeful, Self - determining, Concrete, Multi - faced, and Emotional. FMCG companies always shows their long-term goal in the vison like NESTLE main focus is "to be a leading, competitive, Nutrition, Health and Wellness Company delivering improved shareholder value by being a preferred corporate citizen, preferred employer, preferred supplier selling preferred products".

\subsection{Core values}

Organizational intellectual assets are unruffled in their decisive essence of knowledge, intelligence, and values. Every component signifies united outcomes of the individual contributions of all employees (Bratianu, 2008). Values denote strong views people get through their education in the family, at school, and in Society as any organization plays the controlling role in any decision-making process. Schein (2004) defined value as A set of beliefs and values that become personified in organizational philosophy. Hence, it can help as a guide and a way of dealing with the indecision of inherently overwhelming or difficult events. All individual personnel values are joined with the organizational level, rendering to the organizational integrators' operational influence. The consequence contains the core corporate values which can be expressed clearly and merged with a mission statement and organizational culture in an unspoken way. Mathur and Kenyon (2012) define the corporate values as a procedure connected to the new perception of Corporate Social Responsibility (CSR), in which ethical values shape the framework of decision-making processes. Besides that, values become the main force for the company that provides a shared edge of the position that assists as a combining force across different functions (Marilyn, M.,2006). Company values are interconnected and shared by all employees for the organizational intellectual capital. According to Waterman \& Peters (1982), the same dominant beliefs of excellent companies is also narrow in scope includes A belief in being the best, details of execution, people as individuals, in superior quality and service, innovators, the willingness to support failure, enhance communication and finally economic growth and profits.

\footnotetext{
2021 | International Journal of Financial, Accounting, and Management/ Vol 2 No 4, 343-355
} 
Shared values define the fundamental character of their organization, the attitude that distinguishes it from all others and creates a sense of uniqueness for those in the organization, making employees feel special and values are a reality in the minds of most people throughout the company, not just confined to the senior executives (Deal and Kennedy, 1983) It is a matter of regret that the least understood and the under-implemented statement is the statement of core values. From the name, it is clearly understood that a core values statement clears an organization's shared beliefs. DuFour and Eaker (2009) claimed that core values statement response to how organizations act to make our shared vision a reality. Jaakson, K. (2010) claimed that When associated with shared values and united in a common Purpose for gaining a competitive advantage. Jaakson, K. (2010) additionally deal with those organizations, centered on powerful, shared values, report better service to their customers, higher profits, and a higher quality of working environments for their employees and also stated that it is these common values that act as the primary expert within an organization. Calder (2011) stretched the thoughtful of the status of values statements by demanding that values statements provide an important introductory column for how business is to be conducted also described Values shape much of the work progressions and, as such, stimulus how an organization moves frontward in a positive way. According to ACME their "company values are the measure for our thinking and actions. They are the core of what ties us together in the past, present and future. We do business based on common values. Our success is based on customerfocus, team spirit, desire to win, pro-activity, integrity and excellence. These values determine our actions in our daily dealing with customers and business partners as well as in our teamwork and our collaboration with each other".

\subsection{Human resource management}

Human resources are the human assets used in an association, and human resource management (HRM) mentions the way to show that human capital is used. Snell and Dean (1992) well-defined human resources as the workforce owning knowledge, skills, experience, and financial value in an organization. Liao \& Huang (2016) stated that human resources management is the policies, actions, and systems that stimulus workers' actions, attitudes, and performance. Drucker (1995) noted that the most significant reserves are no longer those in machines, buildings, land, or equipment but those in people and knowledge because Human resources are tangible and valuable assets. Human resource management mainly follows human capital theory and human asset accounting back in the 1970s. The contemporary view of HRM first grew in importance in 1981 with its outline on the prestigious MBA course at Harvard Business School and provided a proposal for many other courses (Boxall, P. F. (1992). At the same time, other explanations were being established in Michigan and New York. These concepts blowout to other countries in the 1980s and 1990s.At the moment, the HRM method is persuasive in many parts of the world as well as seen as a distinct feature. The approach to managing people, drawn sharply from outdated personnel management (Storey, 1989).

Personnel management was normally regarded as having an operational focus, highlighting technical skills and daily functions such as recruitment and selection, training, salary administration, and employee relations. On the other hand, HRM was often depicted as being proactive means looking at people in economic terms as assets. HRM was seen to be strategic, which is tying people management to organizational goals. HRM was seen as a combined style that delivers an articulate program, linking all aspects of people management that ultimately met business needs. Furthermore, HRM was seen to be holistic which concerned with the overall people supplies of an organization. It showed a significant change towards more conceptual, higher-level concerns such as vision, mission, and corporate goals. HRM is also denoted as a constant view of people management in which staffs were treated as treasured as assets $\underline{(\text { Price,2004). }}$

Lengnick-Hall et al., (2009) identified a clear foundation for accepting the HRM approach by ensuring that an organization's people are considered as well as its financial and technological resources when objectives are set or capabilities assessed. Besides that, taking Human capital into consideration of the individuals who implement and comprise the strategy and also encouraged the formulation of strategy as a potential source of organizational competence and competitive advantage. Many Scholars in the HR and management literature contend that major human resource decisions should be linked with 
human capital. Human resource management mainly focuses on three aspects firstly Planning and organizing for work through people and HRM Strategic perspective, Organization design Change management, Corporate' wellness' management secondly People acquisition and development through Staffing the organization, Training and development, Career management, Performance management, Industrial relations and Finally administration of policies through programs and practices, Compensation management, Information management, Administrative management, and Financial management. No organization will not get competitive advantages if it does not focus on the most critical asset: human capital. For this reason, most renowned FMCG companies like British American Tobacco said that "We are committed to building A Better Tomorrow for all our stakeholders."

\subsection{Fast-Moving Consumer Goods (FMCG)}

Consumer goods are stated as to the final goods and services that are consumed by the families and not used in the manufacturing procedure of other goods \& services. Consumption of these goods and services is defined as Private Household Consumption. In contrast, Fast Moving Consumer Goods (FMCG) are goods that are traded swiftly and at reasonably lesser cost such as packaged foods, beverages, toiletries, drugs, and so on. Typically, FMCGs have a short shelf life because of highly perishable in nature such as meat, fruits, vegetables, dairy products, and baked goods. Some products also have high turnover rates alike toiletries, packaged foods, soft drinks, housework products. Though the returns margin from the FMCGs is relatively small these goods are normally sold in bulk numbers to make large combined earnings. The business of FMCGs is measured as the most conclusive example of low margin and high-volume business. FMCGs industry is one of the wildest rising sections of the market. The population of Bangladesh was 164.67 million at the end of 2017 and This large population of the country makes the FMCGs industry very potential. With the considerable growth of GDP, private consumption growth has also increased over the years. In FY 2016-17, GDP Growth rate was 7.28\% compared to 7.11\% in FY 2015-16 whereas Private consumption growth in FY 2016-17 was 10.3\% compared to $9.1 \%$ in FY 2015-16. Bangladesh Bureau of Statistics (BBS) stated that consumer spending was $96 \%$ of average monthly household earning in 2010 where it was $83 \%$ in 2005 and $78 \%$ in 2000 . Consumption spending was $93 \%$ of average monthly household income in 2010 compared to $79 \%$ in 2005 and $74 \%$ in 2000. From this past trend, it can be said that the consumption expenditure as \% of total income has increased significantly over the periods both in urban and rural areas.

In Bangladesh, the FMCG industry can be classified into three major groups- Foods and Beverage, Personal Care, and Household Care Industries. The foods and Beverage Industry includes all food products such as milk \& dairy products, biscuits, bakery products, frozen foods, ice cream, tea, coffee, baby foods, soft drinks, tobacco, etc. On the other hand, the Personal Care industry includes products that are used for personal care like perfume, cosmetics, toiletries products, and other related products. Household products include the products which are useful to maintain the house, like cleaning and decorating. It includes room scents or sprays, detergent powder, liquid detergent, soap noodles, and related products (Ashik,2018).

Popular foods \& beverage companies in Bangladesh are Acme Agro Vet \& Beverages Ltd, ACI Foods Limited, Akij Food \& Beverage Ltd, Aarong, BD Foods Limited, Bashundhara Foods \& Beverage Industries Limited, Bombay Sweets \& Company Ltd, British American Tobacco Limited, Cocola Food Products Limited, Dhaka Tobacco Limited, Golden Harvest Agro Industries Limited, Globe Soft Drink Ltd, Haque Group of Industries, Ifad Foods Limited, Ispahani Foods Limited, Meghna Group of Industries, Nestle Bangladesh, New Zealand Dairy Products Bangladesh Limited, Nabisco Biscuits \& Bread Factory Ltd, Olympic Industries Limited, Pran RFL Group, Partex Beverage Ltd, Perfetti Van Melle Private Limited, Prome Agro Foods Limited, Square Foods \& Beverage, Sajeeb Group, Transcom Beverages and others. The cosmetics and toiletries industry are mainly dominated by the international brands where quality issue surpasses the pricing of products amidst the factors influencing the buying decisions. Local manufacturers produce lower-priced toiletries and perfumes under their own brands focusing middle to low price market niche. Local firms facing difficulties to compete with multinational brands due to trade liberalization. 7 firms control around 95\% of the total market: Unilever, Keya Cosmetics, Lily Cosmetics, Marks \& Allys, Aromatic Cosmetics, Square Toiletries and Kohinoor Chemical Company (Source: Japan Bangladesh Business Centre). The cosmetics industry is 
highly import-oriented. $90 \%$ of the cosmetic chemicals are imported from different countries. Bangladesh usually imports from India, Singapore, Uganda, Thailand and China. Bangladesh imports $41 \%$ of total imported cosmetic goods from India. According to Euromonitor International, the global home care industry witnessed 5\% growth in 2016 and reached USD 143 billion. Home care industry in Asia pacific region experienced 5.70\% YoY growth in FY 2016-17. Online shopping is a major catalyst which driving the home care industry worldwide. Tissue \& Hygiene products noted 205\% CAGR and Home Care products recorded 142\% CAGR since 2012 to 2016 which traded through internet retailing (Ashik,2018). The reason behind choosing this FMCG is that they have a great contribution in the economy because of their popularity and availability both in urban and rural areas. Furthermore, these companies are selected because of their popularity among the youngsters for their dream job. Besides that, they are sort of consideration as the ideal in their industry.

\subsection{Relationship between mission, vision, core values and HR focus}

Mission statements can differ in length, content, format, and specificity (David et al,2014). However, mission statements should be informative, inspiring, enduring, concise, clear, and conducive to employees forming an emotional bond with the firm. Most practitioners and academicians of strategic management proclaim that an effective mission statement should include nine components: 1) customers, 2) products or services, 3) markets, 4) technology, 5) concern for survival, growth, and profitability, 6) philosophy, 7) self-concept, 8) concern for public image, and 9) concern for employees mainly ask the question like Are employees a valuable asset of the firm? Rajasekar, J. (2013). The study investigates the quality of a mission statement is based on stakeholder theory (Donaldson and Preston, 1995). This method examines mission statements to determine if specific stakeholder groups are identified. Bart (1997) studied 88 mission statements and found that customers were cited $78 \%$ of the time, employees $52 \%$, investors $41 \%$, society $33 \%$, and suppliers $21 \%$ of the time. Likewise, Leuthesser and Kohli (1997) observed the content of 63 mission statements and found that $91 \%$ mentioned customers in their statement, $67 \%$ mentioned employees, $60 \%$ mentioned shareholders, and $16 \%$ mentioned suppliers. Based on these studies, each mission statement was examined to identify these five specific stakeholders' groups: customers, employees, investors, suppliers, and society. In this study, we used human resource focus, which is mainly related to the employees and if there is any word related to it as the HR focus FMCG. The literature on mission statements has recommended several other descriptive variables for the determinants of stakeholder inclusion in mission statements. According to Bartkus et al. (2004), mission statements in Japan refer to fewer stakeholder groups than mission statements in Europe and the USA. From the study by Bartkus et al. (2004) it also becomes clear that Japanese mission statements less frequently refer to resource providers (i.e., employees and investors), but more frequently refer to non-resource providers (i.e., society) in comparison to mission statements from Europe and the USA. The author has chosen the following parameters: stakeholder values, better place to work, teamwork, employee wellbeing, leadership, corporate citizen, quality growth people and business partners as the buzzword to reflect HR focus. This study would prove that that particular company has a positive relationship with HRM.

\section{Research methodology}

A total of 14 FMCG companies were selected from four different categories. For this study, four food and beverage companies were being used and are PRAN \&RFL, NESTLE, COCA-COLA, and Danish, for personal and household care five companies were used and they were Unilever, Reckitt Benckiser Group plc (RB), P\&G, Partex Star Group (PSG) and MARCO BANGLADESH. For pharmaceutical industries Square, ACME, and Eskayef Pharmaceuticals Ltd. Finally, British American Tobacco and Akij group had been used for tobacco industries. For this study qualitative research means any type of research that produces findings not arrived at by statistical procedures or other means of quantification' has been used (Strauss and Corbin,1998). The data was collected from the company's websites to identify their vision, mission, and core values and investigate their concern towards human resource management. It is an empirical study of the textual data given in the study and various previous document analyses. To assess qualitative research rigor, this study has used credibility test instead of validity by asking questions like, how context-rich and detailed are the basic descriptions? are areas of uncertainty identified? And for dependability instead of reliability asked some questions like are 
research questions clearly defined and the features of the study design congruent with them? Are basic paradigms and analytic constructs clearly specified? Qualitative research is about interpretation (Blumer 1969; Strauss and Corbin 1998; Denzin and Lincoln 2003) or understanding (Frankfort$\underline{\text { Nachmias and Nachmias 1996). It involves collecting and using a variety of empirical materials (Denzin }}$ and Lincoln 2005; Silverman 2013) and approaches (Silverman 2005; Flick 2007). It focuses not only on the objective nature of behavior but also on its subjective meanings: individuals' own accounts of their attitudes, motivations, behavior (McIntyre 2005; Creswell 2009), events and situations what people say and do in specific places and institutions (Goodwin and Horowitz 2002) in social and temporal contexts (Morrill and Fine 1997). Content analysis was used to analyze the mission and value statements. The procedure has been considered a reputable approach for analyzing communication contents for many years. Indeed, several studies have used this tool to study Web content (Rafaeli and Sudweek, 1997; Ju-Pak, 1999; Evans, M. P. 2013). Each company "Home" page was accessed using the web address, and the firm's "About Us" section for finding the statement. The research question dealt with the mission statements' quality based on whether they identified specific HRM perspective. The words "employees," "our people," and "workforce" identified a reference to employees and if those words are there then in considered as the HR focus. Qualitative research has been used to understand the nature and motivation behind the vision, mission, and core values of FMCG.

\section{Results and discussions}

The mission and vision statement of the association includes various things rather than a single component. It is an amalgamation of the core values of the group on which the organization working. To keep a broader perspective mission and vision focus, the organizations give due attention to various stakeholders either insider or an outsider like customers, product and services, market, technology, concern for survival, growth, and profitability, concern for social welfare, and concern for employees. For the quantitative analysis, the companies in groups of four are structured. The author then used website data to see if the companies fulfill specific parameters and, if so, what measure. The following parameters have been chosen $\mathrm{t}$ : stakeholder values, a better place to work, teamwork, employee wellbeing, leadership, corporate citizen, quality growth people and business partners are the buzzwords and those will help to identify that if any companies have them in their mission and vision they will be considered. If any company does not have these types of buzzwords, they will be considered not to pay attention to human resource management.

Table 1. Categories related to the mission, vision and core values of the FMCG

\begin{tabular}{|c|c|}
\hline Categories & Statement \\
\hline People & $\begin{array}{l}\text { - Be a great place to work where people are inspired to be the best } \\
\text { they can be. } \\
\text { - Allowing our people, our shareholders, and the communities in } \\
\text { which we live and work to prosper. }\end{array}$ \\
\hline Partners & $\begin{array}{l}\text { - Nurture a winning network of employees, customers and } \\
\text { suppliers, together we create mutual, enduring value. }\end{array}$ \\
\hline Leadership: & - The courage to shape a better future \\
\hline stakeholders' value. & $\begin{array}{l}\text { - Sustainable world class company to ensure superior customer } \\
\text { satisfaction and stakeholders' value. } \\
\text { - ensuring benefit to the shareholders, stakeholders and the society } \\
\text { at large. } \\
\text { - A better tomorrow for all stakeholders. }\end{array}$ \\
\hline Respect & - Innovation, customer focus \& quality, agility and respect \\
\hline business partners & $\begin{array}{l}\text { - Daily dealing with customers and business partners as well as in } \\
\text { our teamwork and our collaboration with each other. }\end{array}$ \\
\hline Team work & $\begin{array}{l}\text { - Culture of working in a team and good relationship } \\
\text { - Internal culture of multidisciplinary and teamwork }\end{array}$ \\
\hline
\end{tabular}

The companies' mission and vision statements were graded with points, according to the degree in which the parameters were attained. If a company does not have a mission or a vision, or a values 
statement, it received zero points. From total of 14 FMCG companies that had been used in this study only five (Akij group, Marco Bangladesh Reckitt Benckiser Group plc (RB), Eskayef Pharmaceuticals Ltd and Danish) of them showed that they have no mention about the human resource management and those companies mainly focus on their long-term goal and their profits like Marco Bangladesh have their vision, "Is to be valued as one of the most responsible global companies in the Terry Towel Industry for its reliable innovations to those who rely on us". And nine of them showed their concern towards human capital by using those buzzwords as previously mentioned. From food and beverage sections PRAN \&RFL mentioned in their mission statement that they aim to generate employment and earn dignity \& self-respect for our compatriots through profitable enterprises, Nestle in vision statement said that to be a leading, competitive, Nutrition, Health and Wellness Company delivering improved shareholder value by being a preferred corporate citizen, preferred employer, preferred supplier selling preferred products and finally COCA-COLA specifically showed that for achieving sustainable, quality growth people is the best method and their agenda is to Be a great place to work where people are inspired to be the best they can be. Besides, their values mainly focus on leadership, accountability, and diversity. For personal and household care segment, in Unilever mission statement they clearly demonstrate that they have a goal to develop people's skills inside and outside of Unilever as well as it has a simple but clear purpose - to make sustainable living commonplace, In P\&G mission statement illustrate that allowing our people to live and work to prosper and finally in the vision statement of Partex Star Group (PSG) to pay extra attention to stakeholders' value with respect as well as to Make Partex Star Group a diversified, sustainable world class company to ensure superior customer satisfaction and stakeholders' value. In the pharmaceutical sector, Square showed the main interest in the human resource by creating social well-being of the investors, employees, and ACME by being business partners to employees and focusing on their teamwork and collaboration with each other. In tobacco industries, especially in British American Tobacco specified by their motto, the last sector is that committed to building A Better Tomorrow for all stakeholders in their vision statement.

These nine industries have shown stakeholder values, better place to work, team work, employee wellbeing, leadership, corporate citizen, quality growth people, and business partners in their statements; hence, these companies validate the hypothesis and have a positive relationship with HR. Numerous studies (Mullane, 2002; Campbell and Yeung, 1991) have described how mission and vision statements can be used to shape a mutual and collective sense of purpose and serve as agenda through which employees' emphasis has been created. Some scholars believe that mission and vision statements tend to enhance motivation, shape attitude \& behavior, cultivate high levels of commitment, and ultimately positively impact employee performance (Mullane, 2002; Collins and Poras, 2005). In recent time most of the business practices that reflect the diversity of the world we serve - the company seeks to build on its record of diversity among employees, consumers, suppliers and other stakeholders, as well as in its advertising and marketing efforts like IBM. Aithal (2016) identified that the benefits of core values and core is related with the employees, students, Team work, self $\&$ mutual respect, responsibility, ethics, etiquette, social service, communication, character \& competency, techno-savvy \& scientific thinking, quest for excellence, courage to innovate, and continuous improvement through life-long learning. Bartkus et al. (2004), mentioned that Japanese mission statements were more likely to motivate employees by stating how the firm will improve society, than U.S. and European firms. Begley \& Boyd (2000) stated that, when a value-based culture is blended with HR policies, the combination sets a stage for coherent vision, mission, clear decision and a sound-making direction. Ireland, \& Hirc, (1992) stated that Mission statements can help focus the organization on what really matters - to itself as well as to its stakeholders.

\section{Conclusion}

This study's general goal is to discover companies' vision, mission, and core values that focus on human resource management. For this study qualitative research has been used and their data was collected from the 14 different company's websites with four different categories, four food and beverage companies, five personal and household care companies, three pharmaceutical industries and two tobacco industries. From nine of them showed their concern for human resource management in mission and vision in various ways and ironically, five of the samples do not keep a focus on the employees in 
their mission statement. It is so because customers in the FMCG sector are not directly served by the employees but by the product. So, they have a wrong belief that If the employees are not satisfied, they can still satisfy the customers. It is so because their vision and mission direct organizations. There has been no research in this aspect so it is wise to say that there has a wide area for future research sometimes, the mediator factors can be used like the owner's intention for setting the organization's vision and mission. Moreover, this study only confides to the FMCG industries it can be done in other sectors with a large number of sample size. Future research may involve surveying the perceptions of more business owners or employees to increase both the internal and external validity of the results in this study.

From all the discussion, the present mission focus of the concerning employees needs to have a relook by the management. They need to make sure that they have a great concern for their most valuable asset: human capital and entitle them to their strategy, vision, and mission. Furthermore, current concerns about employees and stakeholders should be revised and significant in their motto to motivate and inspire employees. Mission statements can give meaning to work and a shared sense of purpose. Vision and mission statements of organization should stress the organization's principal focus and its activities should be updated more frequently. They should be studied regularly to know the level of implementation and how they contribute to the organization's performance. Also, employees in organization understand the usefulness of vision and mission statements and actually a sizeable number of them have first-hand understanding that they exist. However, management should employ strategies to get them familiar with it on a more regular basis. Finally, the understanding that vision and mission statements are exclusively meant for management or leadership is very usual among employees, nevertheless, they understand their significance to the organization. They encourage individuals to place the firm's prime objectives ahead of individual self-interest. As this research is only confined to the understanding of HR focus vision and mission, they should also focus on their impact so that performance can be improved and attract a more talent pool.

\section{Acknowledgments}

As the study is self-funded, the author wishes to thank those companies that helped collect data used in the study.

\section{References}

Aithal, P. S. (2016). Creating innovators through setting up organizational vision, mission and core values: a strategic model in higher education. International Journal of Management, IT and Engineering, 6(1), 310-324.

Ashik, A. (2018). FMCG Industry Review of Bangladesh. EBL Securities Limited Research, 1-7. (Eighth Edition), Prentice Hall, London.

Baetz, M.C. and Bart, C.K. (1996), Developing mission statements which work. Long Range Planning, 29(4), 526-33.

Bartkus, B., Glassman, M. and McAfee, R.B. (2004). A comparison of the quality of European, Japanese and US mission statements: a content analysis. European Management Journal, 22(4), 393-401.

Begley, T. M., \& Boyd, D. P. (2000). Articulating corporate values through human resource policies. Business Horizons, 43(4), 8-8.

Blumer, Herbert. (1969). Symbolic interactionism: Perspective and method. Berkeley: University of California Press

Boerema, A. J. (2006). An analysis of private school mission statements. Peabody Journal of Education, 81(1), 180-202.

Boxall, P. F. (1992). Strategic human resource management: beginnings of a new theoretical sophistication? Human resource management journal, 2(3), 60-79.

Bratianu, C. (2008). A dynamic structure of the organizational intellectual capital. Knowledge management in organizations, 233-243.

Calder, W. B. (2011). Institutional VVM statements on websites. Community College Enterprise, 17(2), 19-27. 
Campbell, A. and Tawadey, K. (1992). Mission and Business Philosophy. Butterworth- Heinemann, Oxford.

Campbell, A., \& Yeung, S. (1991). Creating a sense of mission. Long range planning, 24(4), 10-20.

Collins, J. C., \& Porras, J. I. (2005). Built to last: Successful habits of visionary companies. Random House.

Creswell, John W. 2009. Research design. Qualitative, quantitative, and mixed method approaches. 3rd ed. Thousand Oaks: SAGE Publications.

Darbi, W. P. K. (2012). Of mission and vision statements and their potential impact on employee behaviour and attitudes: The case of a public but profit-oriented tertiary institution. International Journal of Business and Social Science, 3(14).

David, M. E., David, F. R., \& David, F. R. (2014). Mission statement theory and practice: a content analysis and new direction. International Journal of Business, Marketing, \& Decision Science, $7(1)$.

Deal, T. E., \& Kennedy, A. A. (1983). Corporate cultures: The rites and rituals of corporate life: Addison-Wesley, 1982. ISBN: 0-201-10277-3. \$14.95. Business Horizons, 26(2), 82-85.

Denzin, Norman K., and Yvonna S. Lincoln. (2003). Introduction. The discipline and practiceof qualitative research. In Collecting and interpreting qualitative materials, ed. Norman $K$. Denzin and Yvonna S. Lincoln, 1-45. Thousand Oaks: SAGE Publications.

Denzin, Norman K., and Yvonna S. Lincoln. (2005). Introduction. The discipline and practice of qualitative research. In the Sage handbook of qualitative research, ed. Norman K. Denzin and Yvonna S. Lincoln, 1- 32. Thousand Oaks: SAGE Publications.

Donaldson, T., \& Preston, L. E. (1995). The stakeholder theory of the corporation: Concepts, evidence, and implications. Academy of management Review, 20(1), 65-91.

Drucker, P. F. (1995). Managing the non-profit organization: Practices and principles. Taylor \& Francis.

DuFour, R., \& DuFour, R. (2009). Revisiting professional learning communities at Work®: New Insights for Improving Schools. Solution Tree Press.

DuFour, R., \& Eaker, R. (Eds.). (2009). On common ground: The power of professional learning communities. Solution Tree Press.

Evans, M. P. (2013). Men in counseling: A content analysis of the journal of counseling \& development and counselor education and supervision 1981-2011. Journal of Counseling \& Development, 91(4), 467-474.

Flick, Uwe. (2007). Designing qualitative research. London: SAGE Publications.

FMCG, P. O. (2016). Problems \& prospects of FMCG sector in Bangladesh (Doctoral dissertation, Southeast University).

Frankfort-Nachmias, Chava, and David Nachmias. (1996). Research methods in the social sciences. 5th ed. London: Edward Arnold.

Goodwin, Jeff, and Ruth Horowitz. 2002. Introduction. The methodological strengths and dilemmas of qualitative sociology. Qualitative Sociology, 25(1), 33-47.

Hinton, K. E. (2012). A practical guide to strategic planning in higher education (Vol. 7). Ann Arbor, MI: Society for College and University Planning.

Ireland, R. D., \& Hirc, M. A. (1992). Mission statements: Importance, challenge, and recommendations for development. Business Horizons, 35(3), 34-42.

Ireland, R.D. and Hitt, M.A. (1992). Mission statements: importance, challenge, andrecommendations for development. Business Horizons, 35(3), 34-42.

Jaakson, K. (2010). Management by values: are some values better than others? Journal of management Development.

Johnson, G., Scholes, K., \& Whittington, R. (2009). Exploring corporate strategy: text \& cases. Pearson education.

Ju-Pak, K. H. (1999). Content dimensions of web advertising: a cross-national comparison. International Journal of Advertising, 18(2), 207-231.

Kooli, C. (2019). Governing and managing higher education institutions: The quality audit contributions. Evaluation and program planning, 77, 101713.McIntyre, Lisa J. 2005. Need to know. Social science research methods. Boston: McGraw-Hill. 
Kose, B. W. (2011). Developing a transformative school vision: Lessons from peer-nominated principals. Education and Urban Society, 43(2), 119-136.

Lengnick-Hall, M. L., Lengnick-Hall, C. A., Andrade, L. S., \& Drake, B. (2009). Strategic human resource management: The evolution of the field. Human resource management review, 19(2), 64-85.

Leuthesser, L. and Kohli, C. (1997), Corporate identity: the role of mission statements. Business Horizons, 40(3), 59-66.

Liao, K. H., \& Huang, I. S. (2016). Impact of vision, strategy, and human resource on nonprofit organization service performance. Procedia-Social and Behavioral Sciences, 224, 20-27.

Lunenburg, F. C. (2010, September). Creating a professional learning community. In National Forum of Educational Administration and Supervision Journal, 27(4), 1-7.

Marilyn, M. (2006). Encyclopedia of management. Thomson Gale.

Mathur, S. S., Mathur, S., \& Kenyon, A. (2012). Creating value: successful business strategies. Routledge.

Morrill, C., \& Fine, G. A. (1997). Ethnographic contributions to organizational sociology. Sociological Methods and Research, 25(4), 424-451. https://doi.org/10.1177/0049124197025004003

Mullane, J. V. (2002). The mission statement is a strategic tool: when used properly. Management Decision.

Pekarsky, D. (2007). Vision and education: Arguments, counterarguments, rejoinders. American Journal of Education, 113(3), 423-450.

Price, A. (2004). Human resource management in a business context.

Rafaeli, S., \& Sudweeks, F. (1997). Networked interactivity. Journal of computer-mediated communication, 2(4), JCMC243.

Rajasekar, J. (2013). A comparative analysis of mission statement content and readability. Journal of Management Policy and Practice, 14(6), 131-147.

Schein, E. H. (2004). Organizational culture and leadership Third edition.

Silverman, David. (2005). Doing qualitative research. A practical handbook. 2nd ed. London: SAGE Publications.

Silverman, David. 2013. What counts as qualitative research? Some cautionary comments. Qualitative Sociology Review, 9(2), 48-55.

Snell, S. A., \& Dean Jr, J. W. (1992). Integrated manufacturing and human resource management: A human capital perspective. Academy of Management journal, 35(3), 467-504.

Stemler, S. E., Bebell, D., \& Sonnabend, L. A. (2011). Using school mission statements for reflection and research. Educational Administration Quarterly, 47(2), 383-420.

Storey, J. (1989). Introduction: from personnel management to human resource management. New perspectives on human resource management, $1,18$.

Strauss, Anselm L., and Juliette M. Corbin. (1998). Basics of qualitative research. Techniques and procedures for developing grounded theory. 2nd ed. Thousand Oaks: Sage Publications.

Waterman, R. H., \& Peters, T. J. (1982). In search of excellence: Lessons from America's best-run companies. New York: Harper \& Row. 


\section{Websites}

http://www.batbangladesh.com/(2019)

https://coca-colafemsa.com/(2019)

https://danishbusinessauthority.dk/(2019)

https://partexstargroup.com/(2019)

https://us.pg.com/(2019)

https://www.acmeglobal.com/(2019)

https://www.akij.net/(2019)

https://www.marcobd.com/(2019)

https://www.nestle-esar.com/(2019)

https://www.pranfoods.net/(2019)

https://www.rb.com/(2019)

https://www.skfbd.com/(2019)

https://www.squarepharma.com.bd/(2019)

https://www.unilever.com/(2019) 